\title{
The ACL Fixation
} \author{
Bățagă ${ }^{3}$, Eduard Marcel Cernat ${ }^{1}$ \\ 1 Department of Orthopedics and Traumatology, Central Military Hospital, Bucharest, Romania \\ 2 "Carol Davila" University of Medicine and Pharmacy, Bucharest, Romania \\ 3 University of Medicine and Pharmacy, Tîrgu Mureș, Romania \\ 4 "Victor Babeș" University of Medicine and Pharmacy, Timișoara, Romania
}

Ion Bogdan Codorean¹, Ștefania Tănase¹, Vlad Predescu², Octav Russu³, Radu Prejbeanu4 ${ }^{4}$, Tiberiu

\section{CORRESPONDENCE}

Ion Bogdan Codorean

B-dul Eroii Sanitari nr. 8

050474 București, Romania

Tel: +40 213180719

E-mail: dr.codorean@traumatologiesportiva.ro
Ștefania Tănase • Str. Mircea Vulcănescu nr. 88, O10825 București, Romania. Tel: +40 213193051 Vlad Predescu • B-dul Eroii Sanitari nr. 8, 050474 București, Romania. Tel: +40 213180719 Octav Russu • Str. Gheorghe Marinescu nr. 38 540139 Tîrgu Mureș, Romania. Tel: +40 265215551 Tiberiu Bățagă • Str. Gheorghe Marinescu nr. 38 , 540139 Tîrgu Mureș, Romania. Tel: +40 265215551 Eduard Marcel Cernat • Str. Mircea Vulcănescu nr. 88, 010825 București, Romania. Tel: +40 213193051

\begin{abstract}
$A C L$ rupture frequently occurs due to a pivotal movement between the tibia and femur. In lack of reconstruction surgery of the ligament, osteoarthritis appears. The ACL graft can be fitted through different systems: compression, expansion and suspension. Although different in technique, the clinical end-results show little differences.
\end{abstract}

Keywords: ACL fixation, surgical reconstruction, fixation types, different techniques

\section{INTRODUCTION, HISTORY AND DESIGN}

Various factors need to be taken into consideration for anterior cruciate ligament (ACL) restoration surgery to be successful, such as patient and graft selection, fixation technique, surgical procedure (approach, tunnel positioning, graft tensioning), and the recuperation plan following surgery. The fixation method is the factor that seems to influence the mechanical features of the graft in the initial period after surgery, therefore it is a key aspect in the physiotherapy protocol. ${ }^{1}$ The main reason of ACL restoration surgery failure seems to be the tunnel placement.

The first ACL reconstruction surgery is attributed to Hay Groves in 1917. In 1930 Ivor Palmer wrote the first monographs on the subject, in which early suturing of the ligament was advocated. Modern treatment began with the work of Macintosh and Erickson, who advocated reconstruction rather than repair of the ACL with patellar tendon. In the 1980s Macintosh pioneered the extraarticular reconstruction, while Erickson replaced it with intra-articular reconstruction. In the 1980s the graft used was from patellar tendon, but due to the improvement of graft preparation and fixation, in the 1990s the semitendinosus tendon graft became more popular. ${ }^{2}$

In 1984 Noyes et al. subjected various tissue grafts for ACL reconstruction in order to evaluate their potency and elongation features, and compared them to the mechanical features of the native, undamaged ACL. They presented an approximation of ACL loading in vivo, throughout usual move- 
TABLE 1. ACL fixation devices and a personal opinion in its popularity

\begin{tabular}{lcc}
\hline & Mechanical fixation & \\
\hline Device & Fixation Type & Popularity \\
\hline Interference screws & Direct - compression & + \\
Press-fit fixation & Direct - compression & - \\
Screw/screw-washer fixation & Direct - compression & - \\
Staples & Direct - compression & + \\
Buttons & Indirect - suspension & + \\
Cross-pins & Indirect - expansion & $+/-$ \\
Aperture fixation & Direct - compression & $-/+$ \\
\hline
\end{tabular}

ments at $454 \mathrm{~N}$ and an ultimate failure load of $1750 \mathrm{~N} .{ }^{3}$ The original biomechanical study of ACL graft fixation was conducted by Kurosaka et al. in 1987. They showed that bone-patellar tendon-bone (BPTB) grafts stabilized with titanium interference screw were superior to staples and sutures tied across buttons from a mechanical point of view. They concluded that the weakest link in ACL surgical restorations is the placement of the fixation, which has, since then, influenced further research. ${ }^{4}$

Nowadays, several fixation systems are accessible for either soft-tissue or bone-tendon-bone (BTB) grafts; a number of studies compare the two grafts, and show significant differences between them, but with excellent clinical results with both methods.

Milano et al. took into consideration three different units to better understand the femur-graft-tibia system: a femoral fixation-site unit, a tendon unit (the graft), and a tibial fixation- site unit. ${ }^{5}$ The graft will influence the use of different stabilizing devices at the femoral and tibial site. The three main fixation characteristics are: strength, slippage and stiffness. Strength, measured in newtons (N), is the characteristic of the graft fixation system to oppose the weight that leads to definitive displacement of the fixation system. The graft fixation device needs to be stiff enough to permit biological assimilation of the graft into the osseous tunnels while restoring the displacement of a given load. The slippage or stretch characteristic concerns modifying the position of the first graft stabilization point at a precise quantity of submaximal load sequences. There are three main types of ACL fixation devices: compression, suspension and expansion (Table 1). ACL fixation methods can also be divided into many ways (Table 2 ).

\section{BIOLOGY}

Based on histological studies, the graft passes through 4 stages of assimilation.

During the initial phase, characterized by acute inflammation, a process of necrosis due to ischemia takes place. Subsequently, chronic inflammation sets in, and the next three stages come about: revascularization, cell proliferation and collagen remodeling. The molecular mechanisms that occur include the resorbtion of intraarticular bleeding, the elimination of debris within the synovial liquid, collagen deposition, the expression of growth factors, and will eventually lead to successful graft assimilation.

The healing process seems to begin with proliferation at the bone-tendon interface with the proliferation of fi-

TABLE 2. Other classification of $A C L$ fixation methods

\begin{tabular}{|c|c|c|}
\hline $\begin{array}{l}\text { - Aperture or intratunnel fixation } \\
\text { - Interference screws } \\
\text { - Cross pins } \\
\text { - Extra-articular fixation } \\
\text { - Cortical fixation devices } \\
\text { - Femoral loops } \\
\text { - Tibial cortical fixation }\end{array}$ & $\begin{array}{l}\text { - Anatomical (aperture or joint line } \\
\text { fixation) } \\
\text { - Non-anatomical (staples, buttons) } \\
\text { - Semi-anatomical (transfixation de- } \\
\text { vices, distal interference fixation) }\end{array}$ & $\begin{array}{l}\text { - Direct fixation (graft anchored to } \\
\text { the tunnel without using additional } \\
\text { material except the fixation device } \\
\text { itself): interference screws/ } \\
\text { staples/ spiked washers } \rightarrow \text { com- } \\
\text { press the graft against the bone } \\
\text { - Indirect fixation (linkage mate- } \\
\text { rial between graft and fixation } \\
\text { device): cross-pin fixation/endo- } \\
\text { buttons/adjustable buttons } \rightarrow \\
\text { suspend the graft within the bone } \\
\text { tunnel }\end{array}$ \\
\hline
\end{tabular}


brovascular tissue. ${ }^{6}$ Depending on the type of graft used, histological findings at the interface between graft and bone differ. In a canine reproduction, complete assimilation was accounted at 12 weeks post-operation. The initial tendon connection in the graft upheld the characteristics of direct connection during the entire healing course, with Sharpey-like fibers found at the border between the patellar tendon and the osseous channel. The tendon-bone interface structure resembled that of a normal ACL. ${ }^{7}$ In a rabbit model, similar works have shown that there might be a significant hold-up prior to any histological confirmation of graft-bone union, the implant of bone-patellar tendon showing the 4-layer integration being apparent at 38 weeks. ${ }^{7,8}$ The hamstring autograft has become more popular due to a couple of advantages, such as: the lack of possible injured extensor apparatus, decreased pain in the anterior knee, and lesser frequency of permanent flexion. Between bone and tendon autograft an indirect type a healing has been identified. In a canine model, Sharpey's fibers were visible at 12 weeks, and that tissue has achieved full development at 26 weeks after the implant took place. ${ }^{7}$

There are not many studies on humans that focus on the interface between graft and bone. Pinczewski et al. obtained tissue from the graft bone interface, and showed that osteointegration of the tendinous tissue and host bone took place between 6 and 15 weeks after surgery. ${ }^{9}$ Another study conducted by Ishibashi et al. analyzed modifications in the histology of the tibial tunnel, and showed that bone-tendon incorporation goes on for a number of months following the implant, with obvious distinction in the structure of the margins. ${ }^{10}$

"Ligamentization" is the process that describes the modifications that take place in the transplanted tendon. It reveals the morphological alterations inside the tendon, including an augmented fibroblast proliferation, and MRI alterations that are represented by enhanced shear resistance and enhanced vascular proliferation. On a histological level, in the first two months fibroblastic ingrowth is predominant, followed by graft remodeling with neovessel development and necrosis in the subsequent 10 months. In the end, a steady maturation occurs over a twoyear period. The transplanted graft undergoes a course of full metaplasia to a ligamentous configuration in 3 years after the implant has been inserted. The biological cycle of proceedings is not necessarily encountered at the border between the graft and the bone. ${ }^{6}$

\section{INTERFERENCE SCREWS}

Interference is the distance by which the diameter of the screw surpasses the gap between the graft and the tunnel.
Interference screws can be used in all types of grafts. The main factors that influence screw fixation are: length, size and geometry of the screw, divergence of the screw, torque of screw insertion, bone mineral density (BMD) and screw material. 5,11

BMD is perhaps the most significant variable that chooses the primary fixation force, rigidity and opposition to sliding during cyclical loading. BMD is lower in females compared to males, and decreases with age. BMD of the tunnel in the tibia is decreased compared to the femoral burrow, therefore a screw with a larger diameter is used for stabilization in the proximal tibia, and the anterior medial region of the tibia is adequate.

Screw length does not show to influence the initial fixation properties, but longer ones are better in hamstring graft.

Screw deviation of more than 15 degrees from tunnel orientation dramatically decreases the fixation strength of the construction.

Three main varieties of interference screws are available: metal, biodegradable and biocomposite. ${ }^{12,13}$ Metal screws were traditionally used for fixation in ACL restorations for several years, with high primary fixation strength while promoting early osseous integration. The disadvantages of using metal interference screws are: possible injury of bone-tendon connection while positioning the screw, posterior cortex damage, the presence of intra-articular hardware, postoperative MRI with distortion images, and the need to remove the hardware in revision surgery. Titanium screws get covered by bone tissue, while steel screws get enveloped by fibrous tissue. ${ }^{11,12}$ Due to the evolution in the field in bioengineering and biomaterials, biodegradable, biomimetic and biocompatible screws were developed. Two main types exist: slow-degradable and fast-degradable screws. Each polymer used has its own properties, such as: polyglycolic acid (PGA), polydioxanone, but better results were discovered by blending different copolymers, such as polyglycolic acid/polylactic acid (PGA/PLA), rising above the limits of one-type polymers. Biocomposite screws use a mixture of the polymers listed, as well as and osteoconductive materials, such as beta tricalcium phosphate or hydroxyapatite, useful in cell adhesion. These types of screws are destined to dissolve over time, but in contrast to biodegradable implants, the osteoconductive properties promote graft assimilation and formation of new osseous tissue.

The scientific literature mentions several downfalls of the use of biodegradable interference screws, such as intraoperative or early postoperative screw breakage, screw 

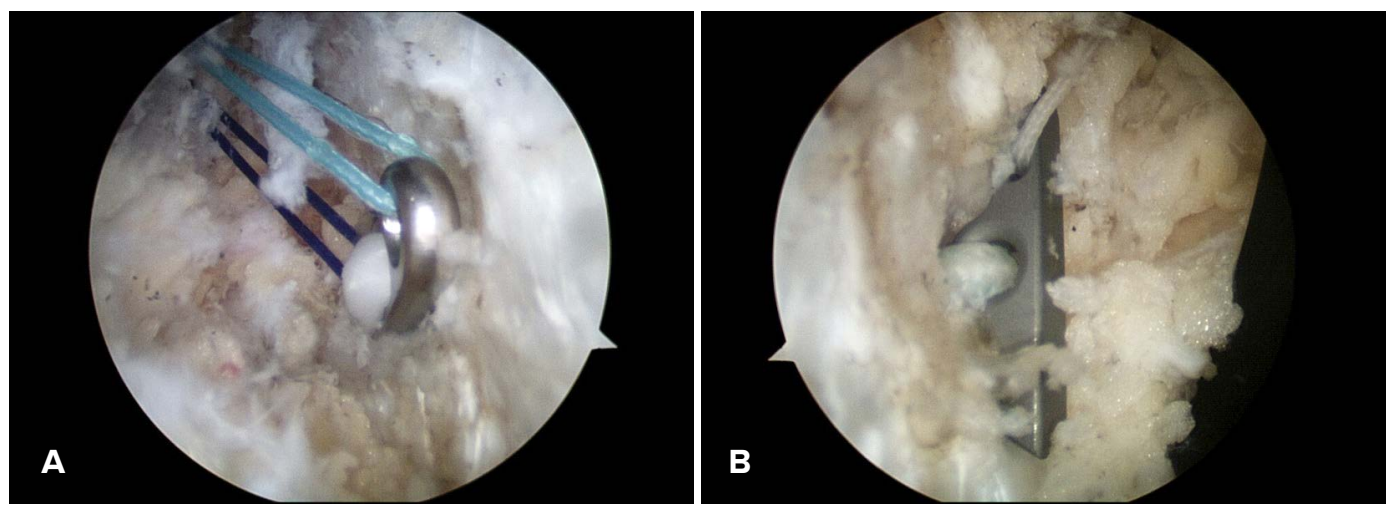

FIGURE 1. Intraoperative femoral cortical fixation. A - Endobuttoon ${ }^{\text {TM }}, \mathbf{B}-$ ToggleLoc $^{\text {TM }}$

migration, foreign body reaction with cyst or abscess formation, tunnel widening over time, and a higher cost compared to metal screws. ${ }^{13-17}$ Popular these days is the use of plastic implants made of polyeteretherketone (PEEK) and polyethylene terephthalate (PET). They do not resorb, are inert, are not responsible for allergic reactions, do not interfere with imaging studies, and in case of revision surgery, they can be overdrilled. ${ }^{5,18}$

\section{BUTTONS}

The button fixation device consists of a metal plate with suture loops. Different companies manufacture different products, such as EndoButton ${ }^{\text {Tix }}$ (Smith \& Nephew, Figure 1A), Tight Rope ${ }^{\text {rux }}$ (Arthrex), ToggleLoc (Biomet, Figure 1B), and many others. The hardware is placed through a tunnel drilled in the femur distally on the anterolateral cortical bone, which suspends the graft in the tunnel. In this type of stabilization method, resistance vectors at the bone-hardware interface are parallel with the cortex of the distal femoral bone, and opposite to pull-out forces. The interface of the fixation device depends on the design of each manufacturer. $5,19,20$

\section{CROSS-PINS}

In the case of cross-pin stabilization, the secure end is close to the joint, and the pin in the tunnel provides graft expansion. The system provides a very solid fixation, with no tunnel movement and no graft damage, the main disadvantage is the need of a long graft. ${ }^{19-22}$

\section{STAPLES}

This type of system provides a solid fixation either in the femur or tibia, usually used in non-anatomical "over the top" ACL reconstruction. The biggest risk is breakage during implantation, and it can be felt under the skin. ${ }^{23}$

\section{COMPLICATIONS}

Complications that occur during ACL restorations can be categorized into intraoperative (technical mistakes) and postoperative complications. The most important intraoperative complication is femoral and tibial tunnel placement, while postoperative complications are: arthrofibrosis, motion problems, infection and hemarthrosis.

An unsuccessful fixation involves loss and slippage, and is a concern for many surgeons. Femoral fixation using EndoButton ${ }^{\text {nt }}$ has excellent biomechanical properties, is able to endure the forces that occur during normal daily activities, and is less susceptible to graft slippage while applying loads. Disruption of the femoral tunnel (back-wall blowout) can happen due to a miscalculation on part of the surgeon, or due to the use of interference screw fixation. When this occurs, the surgeon must be familiar with other fixation techniques, such as cross pins or two-incisions techniques to allow for fixation on the femoral cortex. The XtendoButton ${ }^{\text {ma }}$ can be fitted on the EndoButton ${ }^{\text {nt }}$ system when the femoral socket is drilled too deep, thus opening the femoral tunnel. ${ }^{24,25}$

Tunnel expansion and widening appear most frequently in the use of autogenous hamstring tendon versus autogenous patellar tendon use. MRI studies have shown that tunnel expansion is due to the accumulation of periligamentous tissue around the graft. Tunnel widening also occurs in certain patients in which biodegradable screw fixation has been employed.

\section{CONCLUSIONS}

The weakest link in the early postoperative period is the fixation system. The most important factor related to ACL 
reconstruction failure is tunnel placement and anatomical reconstruction. Clinical outcomes for different devices are similar. Tibial fixation is at greater risk due to its low BMD compared to the femoral one, and we believe that a hybrid fixation at this level is a better choice.

\section{CONFLICT OF INTEREST}

Nothing to declare.

\section{REFERENCES}

1. Brand J Jr, Weiler A, Carbon DN, et al. Graft fixation in cruciate ligament reconstruction. Am J Sports Med. 2000;28:761-774.

2. Murray MH. History of $A C L$ treatment and current gold standard of care; in Murray $\mathrm{MH}$, Vavken P, Fleming $\mathrm{BC}$ (eds), The $\mathrm{ACL}$ handbook: knee biology, mechanics, and treatment; Springer, NY. 2013. p. 19-28.

3. Noyes FR, Butler DL, Grood ES, et al. Biomechanical analysis of human ligament grafts used in knee-ligament repairs and reconstruction. J Bone joint Surg Am. 1984;66:344-352.

4. Kurosaka M, Yoshiya S, Andrish JT. A biomechanical comparison of different surgical techniques of graft fixation in anterior cruciate ligament reconstruction. Am J Sports Med. 1987;15:225-229.

5. Milano G, Petersen W, Hoeher J, et al. Fixation; in Siebold, Dejour D, Zaffagnini S(eds), ACL Reconstruction: A practical Surgical Guide, Springer, Heidelberg, 2014. p. 215-266.

6. Deehan DJ, Cawston TE. The biology of integration of ACL. JBJ Surg. 2005;87:895-899.

7. Rodeo SA, Arnoczky SD, Torzilli PA, Hidaka C, Warren RF. Tendon-healing in a bone tunnel: a biomechanical and histological study in the dog. $J$ Bone Joint Surg. 1993;75A:1795-1803.

8. Schiavonne PA, Fabbriciani C, Delcogliano A, Franzese S. Bone-ligament interaction in patellar tendon reconstruction of the ACL. Knee Surg Sports Traumatol Arthrosc. 1993;1:4-8.

9. Pinczewski LA, Clingeleffer AJ, Otto DD, et al. Integration of hamstring tendon graft with bone in reconstruction of ACL. Arthroscopy. 1997;13:641-643.

10. Ishibashi T, Toh S, Okamura Y, Sasaki T, Kusami T. Graft incorporation within the tibial bone tunnel after ACL reconstruction with bone-patellar tendon bone autograft. Am J Sports Med. 2001;29:473-479.

11. Caborn DN, Urban WP Jr, Johnson DL, Nyland J, Pienkowski D. Biomechanical comparison between BioScrew and titanium alloy interference screws for patellar tendon bone graft fixation in $\mathrm{ACL}$ reconstruction. Arthroscopy. 1997;13:229-232.
12. Weiler A, Hofmann RF, Stahelin AC, Helling HJ, Südkamp NP. Biodegradable implants in sports medicine: the biological base. Arthroscopy. 2000;16:305-321.

13. Konan S, Haddad FS. The unpredictable material properties of bioabsorbable PLC interference screws and their adverse effects in ACL reconstruction surgery. Knee Surg Sports Traumatol Arthrosc. 2009;17:293-297.

14. Bernstein A, Tecklenburg K, Südkamp P, Mayr HO. Adhesion and proliferation of human osteoblast-like cells on different biodegradable implant materials used for graft fixation in ACL-reconstruction. Arch Orthop Trauma Surg. 2012;132:1637-1645.

15. Ciccone WJ, Motz C, Benteley C, Tasto JP. Bioabsorbable implants in orthopaedics: new developments and clinical application. J Am Acad Orthop Surg. 2001;9:280-288.

16. Pavarinta U, Bostan O, Majola A, Toivonen T, Tormala P, Rokkanen P. Intraosseous cellular response to biodegradable fracture fixation screws made of polyglycolide or polylactictide. Arch Orthop Trauma Surg. 1993;112(2):71-74.

17. Bos RR, Rozema FR, Boering G, et al. Degradation of and tissue reaction to biodegradable PLLA for use of internal fixation of fractures: A study in rats. Biomaterials. 1991;12:32-36.

18. Vert M, Mauduit J, Li S. Biodegradation of PLA/ PGA polymers. Increasing complexity. Biomaterials. 1994;15:1209-1213.

19. Boden RA, Razak A, Hussain SMA, Mcloughlin SJ. Loose body following cross-pin fixation for ACL resconstruction. J Orthop Traumatol. 2013;15:155-157

20. Petre BM, Smith SD, Jansson KS, et al. Femoral Cortical suspension devices for soft tissue $\mathrm{ACL}$ reconstruction: a comparative biomechanical study. Am J Sports Med. 2013:41:416-422.

21. Wei Q, Yujie L, Xue J, Haifeng L, et al. Applying cross-pin system in both femoral and tibial fixation in ACL reconstruction using hamstring tendons. Arthosc Tech. 2015;4:397-402.

22. Kong CG, Yong I, Geon Hyeong K. Cross Pins vs Endobutton Femoral Fixation in Hamstring ACL reconstruction: min 4 year follow-up. Knee Surg Relat Res. 2012;24:34-39.

23. Marcacci M, Zaffagnini S, lacono F, Neri MP, Loreti I, Petitto A. Arthroscopic intra and extras-articular ACL reconstruction with gracilis and semiteninosus tendons. Knee Surg Sports Traumatol Arthrosc. 1998;6:6875.

24. Basson B, Philippot R, Neri T, Meucci JF, Boyer B, Farizon F. The effect of femoral tunnel widening on one-year clinical outcome after $A C L$ reconstruction using Ziploop ${ }^{\circledR}$ technology for fixation in the cortical bone of the femur. Knee. 2016;23:233-236.

25. Saygi B, Araman O, Sirin E, Arslan I, Demir Al, Oztermeli A. Comparison of different femoral fixation implants and fit techniques for tunnel widening and clinical outcome in $\mathrm{ACL}$ reconstruction using hamstring autograft. Arch Orthop Trauma Surg. 2016;136:241-247. 